\title{
Mutation allele-specific multiplex PCR for the detection of BRAFV600E mutations in breast carcinomas
}

\author{
RAFIQA EACHKOTI ${ }^{1}$, SANAH FAROOQ ${ }^{1}$, RUBY RESHI ${ }^{2}$, MUNEEB U. REHMAN ${ }^{1}$, \\ TABASSUM RASHID $^{1}$, NISAR AHMED NAIKOO ${ }^{1}$, SHAJURUL AMIN ${ }^{3}$ and AKBAR MASOOD ${ }^{3}$ \\ ${ }^{1}$ Department of Biochemistry, Government Medical College and Associated Hospitals, \\ Srinagar, Jammu and Kashmir 190010; ${ }^{2}$ Department of Biochemistry, University of Kashmir, \\ Srinagar, Jammu and Kashmir 190006; ${ }^{3}$ Department of Pathology, Government Medical College \\ and Associated Hospitals, Srinagar, Jammu and Kashmir 190010, India
}

Received February 2, 2019; Accepted June 4, 2019

DOI: 10.3892/wasj.2019.14

\begin{abstract}
The oncogenic activation of BRAF is commonly reported in human cancers; however, it is an understudied research area in breast cancer. In this study, we took the initiative to screen breast cancer patients for the most prevalent hotspot BRAFV600E mutation and discuss its clinical implications. Mutational screening was performed using a highly sensitive technique, mutation allele-specific multiplex PCR (MASMP), the results of which were previously confirmed by sequencing the product and sensitivity compared to direct DNA sequencing. In total, BRAFV600E mutation status was analysed in 50 breast tumour samples and an equal number of adjacent normal tissues. Mutational screening by MASMP revealed its presence in $12 \%$ of the breast cancer patients. Association analysis revealed that BRAFV600E mutation was significantly present in oestrogen receptor (ER)/progesterone receptor (PR)-negative $\left(\chi^{2}=4.36, \mathrm{P}=0.03\right)$ and mostly in triple-negative breast cancers (TNBCs) $\left(\chi^{2}=2.5, \mathrm{P}=0.11\right)$. In addition, although not significant, BRAFV600E-positive breast cancers were mostly found in older-aged $\left(\chi^{2}=1.10, \mathrm{P}=0.29\right)$ and in post-menopausal women $\left(\chi^{2}=1.10, P=0.29\right)$. No significant association was found between BRAFV600E-mutated breast cancers and traditional poor prognostic factors, such as clinical tumour stages III and IV $\left(\chi^{2} 0.036, P=0.84\right)$ and a poorly differentiated (PD) histopathological grade $\left(\chi^{2} 0.04, \mathrm{P}=0.82\right)$.
\end{abstract}

Correspondence to: Dr Rafiqa Eachkoti, Department of Biochemistry, Government Medical College and Associated Hospitals, Karan Nagar, Srinagar, Jammu and Kashmir 190010, India

E-mail: rafiqahaq@gmail.com

Abbreviations: IDC, infiltrating ductal carcinoma; IBC, inflammatory breast carcinoma; MASMP, mutation allele-specific multiplex PCR; PD, poorly differentiated; MD, moderately differentiated; WD, well differentiated

Key words: breast cancer, BRAFV600E/BRAFc.1799T >A mutation
On the whole, positivity for BRAFV600E was noted in a fraction of elderly post-menopausal women, predominantly of the ER/PR-negative and/TNBC molecular subtype. MASMP was found to be a simple, sensitive and effective method for the rapid detection of BRAFV600E-mutated breast cancers. For these types of breast cancers, BRAF-targeted therapies in place of endocrine therapy, at least in BRAFV600E-positive ER/PR-negative/TNBC, may be considered as possible targeted therapy in the future.

\section{Introduction}

Breast cancer exhibits geographical variation as regards incidence. In the US alone, in 2018, an estimated 266,120 women were diagnosed with breast cancer and an additional 40,920 women succumbed to the disease (1). By the year 2030 , it has been projected that there will be 294,000 new cases, thus making breast cancer a growing public health concern (1). In Kashmir (North India), as per population-based cancer registries (HCR) under the National Cancer Registry (NCR) programme maintained in SMHS and in the Regional Cancer Centre (RCC) SKIMS, cancer of the breast is the 2nd leading type of cancer among females with an incidence of $16.3 / 100,000$ population/year, which is less than what is reported for other states in India, such as Mumbai, Delhi, Bangalore, Bhopal, Ahmadabad, Kolkata and Chennai, where breast cancer is leading type of cancer among women with an incidence of 25.8 per 100,000 individuals (2-4). Breast cancer, although a heterogeneous disease, exhibits a high cure rate, possibly due to increased screening, early detection and the use of targeted anticancer therapies. Although a number of risk factors are associated with the disease, such as early menarche, late menopause, late-age marriages and nulliparity, the genesis of the disease involves a number of genetically predisposed genes (BRCA genes), tumour suppressors (TP53, Pten, p16) and oncogenes of the mitogen-activated protein kinase (MAPK), phosphoinositide 3-kinase (PI3K) and insulin-like growth factor 1 (IGF-1) signalling pathways (5).

BRAF is a member of the Raf-Ras-MAP kinase family proteins, weighing $75-100 \mathrm{kDa}$. It is the most important activator of MEK kinase in the Ras/Raf/MEK/ERK 
pathway (6). BRAF mutation is a typical cause of aberrant extracellular-signal-regulated kinase (ERK) signalling (7). BRAF mutation was first reported in 2002 and $90 \%$ of the mutations found are missense mutations at nucleotide 1796, which result in a valine to glutamic acid substitution at codon 600 (7). BRAFV600E mutation has been reported at different frequencies in various neoplasms, such as malignant melanoma (40-70\%), colorectal carcinoma (5-22\%), thyroid papillary carcinoma (36-53\%), glioma (11\%), ovary serous carcinoma (30\%), lung adenocarcinoma (4\%) and hairy cell leukaemia (100\%) (8). It has been previously demonstrated that $10 \%$ of breast cancer cell lines harbour BRAF mutations (9), suggesting the possible presence of BRAF mutations in breast cancer tissues as well. At least to the best of our knowledge, only a few studies on BRAF mutation detection in breast cancer tissues have been performed to date using sequencing methods $(10,11)$. The Sanger sequencing method is the gold standard method for the detection of mutations; however, this method not highly sensitive, costly and requires expensive equipment and expertise (12). To overcome these drawbacks, in this study, we utilized previously developed highly sensitive mutation allele-specific multiplex PCR (MASMP) as an effective surrogate method for evaluating BRAFV600E mutations in breast cancer patients (13).

The aim of this study was to use MASMP as a simple and sensitive screening tool for determining the frequency of BRAFV600E mutation, its association with immune markers [oestrogen receptor (ER), progesterone receptor (PR) and human epidermal growth factor receptor (HER)] and indicators of prognosis and outcome in patients with breast cancer from the Kashmir valley in India, since such data from this region are not available in the literature; we also discuss its clinical implications.

\section{Materials and methods}

Patient selection, histological and immune marker evaluation. In this study, patients attending the Medical Oncology Department at the SMHS Hospital of Government Medical College (GMC), Srinagar, Jammu and Kashmir, India, between February, 2015 and December, 2018 for breast cancer management, were recruited in this study, with prior informed consent. A total of 50 surgical tumour specimens and an equal number of adjacent normal tissues were collected as the controls. The patients underwent a histopathological examination to establish the clinical profile. Patients who had received pre-operative chemotherapy or hormone therapy were excluded. This study was approved by the Institutional Ethics Committee of GMC. All cases were reviewed by a pathologist with haematoxylin and eosin (H\&E)-stained slides. The histological grade was assessed using the Nottingham grading system. Clinicopathological parameters evaluated in each case included patient age at initial diagnosis, tumour histological type, clinical tumour staging, lymph node metastasis and histopathological grade. The immune markers, ER, PR and HER-2, were also evaluated. ER/PR was considered positive even when $\geq 1 \%$ tumour cells exhibited nuclear staining. HER-2 staining was analysed according to the American Society of Clinical Oncology (ASCO)/College of American Pathologists (CAP) guidelines (14). HER-2 immunostaining was considered positive when strong (3+) membranous staining in at least $30 \%$ of the tumour cells was observed, whereas cases with 0 to $1+$ were regarded as negative.

DNA isolation and MASMP analysis. High-molecular-weight DNA was isolated from the tissue samples of the breast cancer patients by proteinase-K digestion and phenol/chloroform extraction [Fan and Gulley (15)]. The extracted genomic DNA was analysed by agarose gel electrophoresis using a UV illuminator (Crystal-BioGlow).

PCR primers. The BRAF mutation primers (BRAF-mut) were designed based on the BRAF sequence, with a mismatched nucleotide at the $3^{\prime}$ end, so that wild-type $B R A F$ was not amplified by these primers. The length of the PCR products was $126 \mathrm{bp}$. In addition, thromboxane A synthase 1 (TBXASI) was selected as a reference gene as an indicator for successful PCR amplification. Information concerning these primers is presented in Table I.

MASMP. BRAF-mut and TBXAS1 genes were amplified in the same 25- $\mu$ l amplification system, which included $30 \mathrm{ng}$ DNA templates, $10 \mathrm{pmol} B R A F$-mut primers, $5 \mathrm{pmol} T B X A S 1$ primers, $0.1 \mathrm{~mol} / \mathrm{dNTPs}$ and 1.5 units Taq enzyme. The thermal cycling protocol for PCR (TAKARA-thermal cycler) involved an initial denaturation step at $95^{\circ} \mathrm{C}$ for $5 \mathrm{~min}$ followed by 30 cycles at $94^{\circ} \mathrm{C}$ for $30 \mathrm{sec}, 54^{\circ} \mathrm{C}$ for $30 \mathrm{sec}$ and $72^{\circ} \mathrm{C}$ for $30 \mathrm{sec}$.

Statistical analysis. All statistical analyses were performed using S-PLUS software (version 8.2, TIBCO software Inc). The Chi-square test was performed to determine the associations between the presence of mutations with various clinicopathological characteristics, such as age, origin, menopausal status, provisional diagnosis, lymph node/s involved, clinical tumour stage and histopathological grade of the tumour. The association between the presence of BRAF mutation with the ER, PR and HER-2 status was also evaluated. $\mathrm{P}<0.05$ was considered to indicate a statistically significant difference.

\section{Results}

Clinical data. In total, 50 breast cancer patients with a mean age at diagnosis of $50.2 \pm 12.3$ years were recruited in the present study; $36 \%(18 / 50)$ of the patients were $<45$ years of age and $64 \%(32 / 50)$ were $>45$ years of age. Among the studied subjects, $36 \%(18 / 50)$ were pre-menopausal and $64 \%$ (32/50) were post-menopausal females. The majority of the patients $(88 \%$; 44/50) were diagnosed with infiltrating ductal carcinomas (IDCs), $8 \%$ with inflammatory breast carcinomas (IBCs) and 4\% with Paget's disease. The majority of cases were of clinical tumour stage II (a,b) 70\% (35/50) followed by stage III and IV $30 \%(15 / 50)$. The lymph node was involved in $80 \%(40 / 50)$ of the cases. Histopathological examination revealed that the majority of cases, $80 \%(40 / 50)$ were of the well and moderately differentiated grade. The majority of the patients under study were ER/PR-positive (70\%) and HER-2 negative (94\%).

MASMP for BRAFV600E mutational detection. We assessed BRAFV600E/BRAFc.1799T $>$ A mutation in 50 breast 
Table I. Mutation allele-specific multiplex PCR primer sequences for the BRAF gene.

\begin{tabular}{llc}
\hline Gene & \multicolumn{1}{c}{ Sequence } & Product size (bp) \\
\hline BRAF-mut & F: 5'-GGTGATTTTGGTCTAGCTACAGA-3' & 126 \\
& R: 5'-GGCCAAAAATTTAATCAGTGG-3' & 100 \\
FBXAS1 & R:-GCCCGACATTCTGCAAGTCC-3' & \\
& &
\end{tabular}

BRAF-mut, BRAFc.1799T>A mutant allele primers; TBXAS1, thromboxane A synthase 1 (reference gene primer sequence).

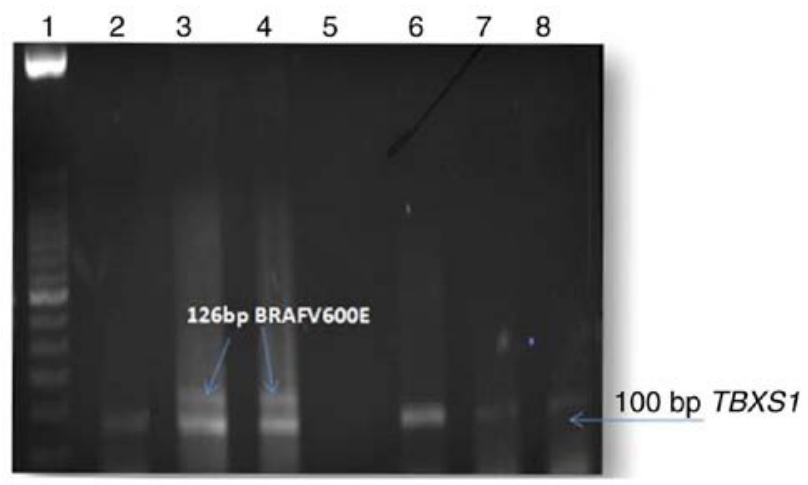

Figure 1. Representative gel image of mutation allele-specific multiplex PCR (MASMP) performed for the BRAFV600E mutational analysis on breast cancer samples. The $126 \mathrm{bp}$ mutant allele is depicted in lanes 3 and 4, against the reference gene band $(100 \mathrm{bp})$ which is positive in all lanes, apart from lane 5. Lane 1 represents the 50 bp ladder. Lanes 2, 6, 7 and 8 represent the $100 \mathrm{bp}$ reference gene band (TBXS1) only without the mutant allele (BRAFV600E). TBXS1, thromboxane A synthase 1.

carcinoma tissues and in an equal number of adjacent normal tissues as controls by MASMP (Fig. 1). MASMP was repeated thrice for each sample. The thick band of the $126 \mathrm{bp}$ product was repeatedly found in the same samples only and not in the controls or presumably BRAFV600E-negative samples in the presence of the $100 \mathrm{bp}$ TBXAS1 reference gene. The authenticity of MASMP in picking up the right product was previously confirmed by sequencing the product using a reverse primer and the sensitivity of the MASMP method was previously investigated and compared with direct DNA sequencing [13]. The association of the BRAFV600E mutation status in the breast cancer patients with the clinicopathological features and immune markers, such as: ER/PR and HER-2 is summarised in Table II. The data regarding the ER/PR and HER-2 status of these patients were collected from pathology department and after reviewing the data in light of the ER/PR and HER-2 status, it appeared that BRAFV600E/BRAFc.1799T $>$ A mutation was significantly present in ER/PR-negative $\left(\chi^{2}=4.36\right.$, $\mathrm{P}=0.03)$ and mostly in triple-negative breast cancers (TNBCs) $\left(\chi^{2}=2.5, \mathrm{P}=0.11\right)$. In addition, although not significant, BRAFV600E-positive breast cancers were mostly found in older-aged $\left(\chi^{2}=1.10, \mathrm{P}=0.29\right)$ and in post-menopausal women $\left(\chi^{2}=1.10, \mathrm{P}=0.29\right)$. No significant association was found between BRAFV600E-mutated breast cancers and traditional poor prognostic factors, such as clinical tumour stages III and IV $\left(\chi^{2} 0.036, \mathrm{P}=0.84\right)$ and a poorly differentiated (PD) histopathological grade $\left(\chi^{2} 0.04, \mathrm{P}=0.82\right)$. However, there is no information regarding KI67, and thus we could not classify BRAF-mutated ER-positive samples into luminal A or luminal B molecular subtypes.

\section{Discussion}

A wealth of data now suggest that molecular aberrations may be shared across multiple histologies. As an example, BRAF is mutated in approximately $15 \%$ of all cancers, either in solid tumours, haematological malignancies and related disease types $(7,16)$. However, the frequencies vary; in some, it is more frequently present in cancers such as melanoma (40-60\%) and hairy cell leukaemia $(100 \%)$ patients $(12,17)$. In others types of cancer, such as breast cancer, the BRAFV600E mutation is uncommon (0-13\%) although BRAF amplification has been reported in $30 \%$ of basal-like carcinomas $(10,11)$. In the present study, BRAFV600E mutation has been found in $12 \%$ of breast cancer patients, which is in conformity with that of Korea, but relatively higher than that reported worldwide (18). Although certain studies have indicated geographical and histological subtype classification factors that may account for these differences in frequencies, the reliability of the detection methods used must also be taken into consideration $(19,20)$. The gold standard method for the detection of BRAF mutation is Sanger sequencing and other PCR-based methods, such as single-strand conformation polymorphism, restriction fragment length polymorphism (RFLP), mass-array spectrometry, pyrosequencing. However, these methods require expensive equipment, high technical skills and are associated with other problems, such as tissue heterogeneity and sampling error. These drawbacks limit their general use in the clinical field (20). To overcome the above-mentioned limitations, in this study, we used previously developed MASMP for BRAFV600E mutational detection in breast cancers (13). It has been previously demonstrated by us and others that the detection sensitivity of MASMP technique is higher than that of direct DNA sequencing $(12,13)$. Our frequency $(12 \%)$ of breast cancers harbouring the BRAFV600E mutation by MASMP was higher than that reported worldwide by various methodologies, but comparable to the immunohistochemistry (IHC) method of detection (13\%) using BRAFV600E mutation-specific antibody (18). As previously demonstrated, while direct sequencing picks up altered alleles from the sample only when the tumour purity is $>60 \%$, MASMP picks up variations even if the tumour purity is $<1 \%$ which may be the reason of the high frequency of mutations detected in the present study (12). These results, therefore, suggest that 
Table II. Association of BRAF gene mutation with clinicopathological features and immune markers of sporadic breast cancer patients from Kashmir, India $(\mathrm{n}=50)$.

BRAF mutation

\begin{tabular}{|c|c|c|c|c|c|}
\hline Feature & Cases & Positive & Negative & $\chi^{2}$ & P-value \\
\hline \multicolumn{6}{|l|}{ Age } \\
\hline$<45$ years & 18 & 1 & 17 & \multirow[t]{2}{*}{1.10} & \multirow[t]{2}{*}{0.29} \\
\hline$<45$ years & 32 & 5 & 27 & & \\
\hline \multicolumn{6}{|l|}{ Living environment } \\
\hline Rural & 30 & 3 & 27 & \multirow[t]{2}{*}{0.28} & \multirow[t]{2}{*}{0.5} \\
\hline Urban & 20 & 3 & 17 & & \\
\hline \multicolumn{6}{|l|}{ Menopausal status } \\
\hline Pre-menopausal & 18 & 1 & 17 & \multirow[t]{2}{*}{1.10} & \multirow[t]{2}{*}{0.29} \\
\hline Post-menopausal & 32 & 5 & 27 & & \\
\hline \multicolumn{6}{|l|}{ Provisional diagnosis ${ }^{\mathrm{a}}$} \\
\hline IDC & 44 & 5 & 39 & \multirow[t]{3}{*}{0.14} & \multirow[t]{3}{*}{0.70} \\
\hline $\mathrm{IBC}+$ & 4 & 1 & 3 & & \\
\hline Paget's disease & 2 & 0 & 2 & & \\
\hline \multicolumn{6}{|l|}{ Lymph node involvement } \\
\hline Yes & 40 & 4 & 36 & \multirow[t]{2}{*}{0.75} & \multirow[t]{2}{*}{0.38} \\
\hline No & 10 & 2 & 8 & & \\
\hline \multicolumn{6}{|l|}{ Clinical tumour staging ${ }^{\mathrm{b}}$} \\
\hline II $(a, b)$ & 35 & 4 & 31 & \multirow[t]{2}{*}{0.036} & \multirow[t]{2}{*}{0.84} \\
\hline III + IV & 15 & 2 & 13 & & \\
\hline \multicolumn{6}{|l|}{ Histopathological grading ${ }^{\mathrm{c}}$} \\
\hline $\mathrm{WD}+\mathrm{MD}$ & 40 & 5 & 35 & \multirow[t]{2}{*}{0.04} & \multirow[t]{2}{*}{0.82} \\
\hline $\mathrm{PD}$ & 10 & 1 & 9 & & \\
\hline \multicolumn{6}{|l|}{ ER/PR status ${ }^{\mathrm{d}}$} \\
\hline Strong + weak positive & 35 & 2 & 33 & \multirow[t]{2}{*}{4.36} & \multirow[t]{2}{*}{0.03} \\
\hline Negative & 15 & 4 & 11 & & \\
\hline \multicolumn{6}{|l|}{ HER-2 status ${ }^{\mathrm{d}}$} \\
\hline Positive & 3 & 1 & 2 & \multirow[t]{2}{*}{1.37} & \multirow[t]{2}{*}{0.24} \\
\hline Negative & 47 & 5 & 42 & & \\
\hline \multicolumn{6}{|l|}{ TNBC $\left(\mathrm{ER}^{-}, \mathrm{PR}^{-}, \mathrm{HER}^{-}\right)$} \\
\hline Yes & 21 & 3 & 9 & \multirow[t]{2}{*}{2.5} & \multirow[t]{2}{*}{0.11} \\
\hline No & 38 & 3 & 35 & & \\
\hline
\end{tabular}

aProvisional diagnosis: IDC, infiltrating ductal carcinoma, IBC, inflammatory breast carcinoma, Pagt, Paget's disease. ${ }^{\mathrm{b}, \mathrm{c}}$ American Joint Committee on Cancer (AJCC) TNM system and histopathological grading. ${ }^{\mathrm{b}}$ Clinical tumour stage: II (a,b), when tumour size ranges from $>2$ and $>5 \mathrm{~cm}$ and metastasis has occurred to ipsilateral axillary nodes, but no metastasis; III $(\mathrm{a}, \mathrm{b})$, tumour of any size and any number of nodes,

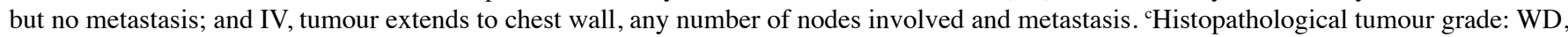
well-differentiated; MD, moderately differentiated; PD, poorly differentiated. ${ }^{d}$ Immune markers A cut-off value of $\geq 1 \%$ positively stained nuclei was used. Values in bold font indicate statistical significance $(\mathrm{P}<0.05)$.

MASMP is a reliable method of mutation detection in clinical samples.

Association analysis revealed that BRAFV600E-mutated breast cancers were characterized by unique clinical-epidemiological and pathological characteristics. Although the absolute number in this study was small, several characteristic features of BRAFV600E-mutated breast cancers have become apparent. A casual association between BRAFV600E-positive breast cancers and an older age $\left(>45\right.$ years; $\left.\chi^{2}=1.10, P=0.29\right)$ and the post-menopausal status of women $\left(\chi^{2}=1.10, \mathrm{P}=0.29\right)$ was observed in the present study (Table II). In addition, a casual association between BRAFV600E-mutated breast cancer and infiltrating ductal carcinoma and lymph node involvement was evident from the present study (Table II), which is in conformity with various other studies (18). No significant association was found between BRAFV600E-mutated breast cancer was found and traditional poor prognostic factors, such as clinical tumour stages III and IV $\left(\chi^{2}=0.036 \mathrm{P}=0.84\right)$ and the PD 
histopathological grade $\left(\chi^{2}=0.04, \mathrm{P}=0.82\right)$. In previous studies, BRAF mutation in different cancer types has been reported to be associated with several clinicopathologic features, such as lymph node metastasis and distant metastasis in papillary thyroid cancer (PTC); younger age and tumour occurrence from intermittently sun-exposed skin in malignant melanoma; poor prognosis in colon cancer which are different from the result from our study regarding breast cancer $(21,22)$. In non-small cell lung cancer, the BRAF mutation status has not been associated with a clinical outcome, such as the result of this study with breast cancer (22). Further association analysis of immune markers revealed that BRAFV600E-positive breast cancers were significantly observed in ER/PR-negative $\left(\chi^{2}=4.36, \mathrm{P}=0.03\right)$ and in the TNBC $\left(\chi^{2}=2.5, \mathrm{P}=0.11\right)$ subtypes, which is in conformity, to a certain extent, to worldwide reports, which have found that BRAFV600E mutation predominantly in TNBC molecular subtype $(11,18)$.

The clinical implication of this study is the potential use of the BRAF mutation status for the application of BRAF targeted therapy in breast carcinomas. Drugs targeting BRAF mutation, such as vemurafenib and dabrafenib, have been approved for BRAF-mutant melanoma based on the results from the phase III BRIM-3 study (23) and the phase III BREAK-3 study (24), respectively. Since the approval of vemurafenib for BRAFV600E-mutated melanoma, accumulating evidence presented in published reports supports the hypothesis that what works for BRAFV600E-mutated melanoma is often also effective for other cancers characterized by the BRAFV600E aberration. For example, dabrafenib for BRAFV600E mutation-positive metastatic non-small cell lung cancer (with a response rate of 54\%) [non-small cell lung cancer (25)]; BRAFV600E-positive papillary thyroid cancer (26)]; BRAFV600E-positive gastrointestinal stromal tumours (27). Complete regression with vemurafenib has been attained in a child with glioblastoma harbouring the BRAFV600E mutation (28), in BRAFV600E-mutated glioma patients (29), in patients with BRAFV600E-mutated hairy cell leukaemia $(9,30)$, and in BRAFV600E mutated Erdheim-Chester disease (31). These studies confirm that multiple histological types of cancer with BRAF mutations respond to BRAF inhibitors, although the precise response rates may differ. Based on the results from the present study and worldwide reports, ER/PR-negative and TNBC molecular subtypes harbour comparatively BRAF mutations or amplifications at a higher frequency. As these subtypes of breast cancer cannot respond to traditional endocrine therapy, BRAF targeted therapy can thus be considered as a possible treatment for these. Thus, screening patients for BRAF mutations may aid in the selection of the initial therapy mode and in the follow-up of these molecular subtypes of breast cancer.

In conclusion, in this study, the positivity for BRAFV600E was noted in a fraction of elderly post-menopausal women, predominantly of the ER/PR-negative and TNBC molecular subtype. MASMP turned out to be a simple and sensitive for the rapid identification of BRAFV600E-mutated breast cancers for which BRAF targeted therapy, in place of endocrine therapy, can be considered a possible targeted treatment in the future. The present study, however, is a preliminary report and studies using larger patient populations are warranted to substantiate the results of this study.

\section{Acknowledgements}

The authors gratefully acknowledge the Pathology Department and Multidisciplinary Research Unit (MRU) of GMC (Government Medical College) Srinagar for providing the equipment for conducting the experiments.

\section{Funding}

No funding was received.

\section{Availability of data and materials}

All data generated or analysed during this study are included in this published article or are available from the corresponding author on reasonable request.

\section{Authors' contributions}

SF performed the research work. RE designed the research study, analysed the data and wrote the manuscript. RR assisted in the selection of histopathologically confirmed breast cancer samples along with their ER/PR/HER-2 status, and in data analysis. MUR, TR and NAN performed the research work. SA and AM analysed the data. All authors have read and approved the final manuscript.

\section{Ethics approval and consent to participate}

This study was approved by the Institutional Ethics Committee of Government Medical College and all patients provided informed consent prior to enrolment.

\section{Patient consent for publication}

Not applicable.

\section{Competing interests}

The authors declare that they have no competing interests.

\section{References}

1. Siegel RL, Miller KD and Jemal A: Cancer statistics, 2018. CA Cancer J Clin 68: 7-30, 2018.

2. Wani MA, Jan FA, Khan NA, Pandita KK, Khurshid R and Khan SH: Cancer trends in Kashmir; common types, site incidence and demographic profiles: National Cancer Registry 2000-2012. Indian J Cancer 51: 133-137, 2014.

3. Qureshi MA, Khan SM, Masoodi MA, Qureshi U, Ain Q, Jan Y, Haq I and Sheikh ZA: Epidemiology of cancers in Kashmir, India: An analysis of hospital data. Adv Prev Med 2016: 1896761, 2016.

4. Malvia S, Bagadi SA, Dubey US and Saxena S: Epidemiology of breast cancer in Indian women. Asia Pac J Clin Oncol 13: 289-295, 2017.

5. Cancer Genome Atlas Network: Comprehensive molecular portraits of human breast tumours. Nature 490: 61-70, 2012

6. Garnett MJ and Marais R: Guilty as charged: B-RAF is a human oncogene. Cancer Cell 6: 313-319, 2004.

7. Davies H, Bignell GR, Cox C, Stephens P, Edkins S, Clegg S, Teague J, Woffendin H, Garnett MJ, Bottomley W, et al: Mutations of the BRAF gene in human cancer. Nature 417: 949-954, 2002.

8. Hall RD and Kudchadkar RR: BRAF mutations: Signalling, epidemiology, and clinical experience in multiple malignancies. Cancer Control 21: 221-230, 2014. 
9. Hollestelle A,Elstrodt F, Nagel JH, Kallemeijn WW and Schutte M Phosphatidylinositol-3-OH kinase or RAS pathway mutations in human breast cancer cell lines. Mol Cancer Res 5: 195-201, 2007.

10. Tilch E, Seidens T, Cocciardi S, Reid LE, Byrne D, Simpson PT, Vargas AC, Cummings MC, Fox SB, Lakhani SR and Chenevix Trench G: Mutations in EGFR, BRAF and RAS are rare in triple-negative and basal-like breast cancers from Caucasian women. Breast Cancer Res Treat 143: 385-392, 2014.

11. Santarpia L, Qi Y, Stemke-Hale K, Wang B, Young EJ, Booser DJ, Holmes FA, O'Shaughnessy J, Hellerstedt B, Pippen J, et al: Mutation profiling identifies numerous rare drug targets and distinct mutation patterns in different clinical subtypes of breast cancers. Breast Cancer Res Treat 134: 333-343, 2012.

12. Sapio MR, Posca D, Troncone G, Pettinato G, Palombini L, Rossi G, Fenzi G and Vitale M: Detection of BRAF mutation in thyroid papillary carcinomas by mutant allele-specific PCR amplification (MASA). Eur J Endocrinol 154: 341-348, 2006.

13. Eachkoti R, Farooq S, Syeed SI, Wani HA, Majid S and Pampori MR: Prevalence and prognostic relevance of Braf V600E mutation in colorectal carcinomas from Kashmir (North India) valley. Mutagenesis 33: 225-230, 2018.

14. Bui MM, Riben MW, Allison KH, Chlipala E, Colasacco C, Kahn AG, Lacchetti C, Madabhushi A, Pantanowitz L, Salama ME, et al: Quantitative image analysis of human epidermal growth factor receptor 2 immunohistochemistry for breast cancer: Guideline from the college of american pathologists. Arch Pathol Lab Med: Jan 15, 2019 (Epub ahead of print).

15. Fan $\mathrm{H}$ and Gulley ML: DNA extraction from fresh or frozen tissues. Methods Mol Med 49: 5-10, 2001

16. El-Osta H, Falchook G, Tsimberidou A, Hong D, Naing A, Kim K, Wen S, Janku F and Kurzrock R: BRAF mutations in advanced cancers: Clinical characteristics and outcomes. PLoS One 6: e25806, 2011.

17. Tiacci E, Trifonov V, Schiavoni G, Holmes A, Kern W, Martelli MF, Pucciarini A, Bigerna B, Pacini R, Wells VA, et al BRAF mutations in hairy-cell leukemia. N Engl J Med 364: 2305-2315, 2011.

18. Jung YY, Jung WH and Koo JS: BRAF mutation in breast cancer by BRAF V600E mutation-specific antibody. Int J Clin Exp Pathol 9: 1545-1556, 2016.

19. Turski ML, Vidwans SJ, Janku F, Garrido-Laguna I, Munoz J, Schwab R, Subbiah V, Rodon J and Kurzrock R: Genomically driven tumors and actionability across histologies: BRAF-Mutant cancers as a paradigm. Mol Cancer Ther 15: 533-547, 2016.

20. Bösmüller H, Fischer A, Pham DL, Fehm T, Capper D, von Deimling A, Bonzheim I, Staebler A and Fend F: Detection of the BRAF V600E mutation in serous ovarian tumors: A comparative analysis of immunohistochemistry with a mutation-specific monoclonal antibody and allele-specific PCR. Hum Pathol 44: 329-335, 2013.

21. COSMIC: Catalogue of Somatic Mutations in Cancer. Wellcome Trust Sanger Institute; http://cancer. sanger.ac.uk/cancer genome/projects/cosmic. Accessed January 2, 2014.
22. Gao J, Aksoy BA, Dogrusoz U, Dresdner G, Gross B, Sumer SO, Sun Y, Jacobsen A, Sinha R, Larsson E, et al: Integrative analysis of complex cancer genomics and clinical profiles using the cBioPortal. Sci Signal 6: pl1, 2013.

23. Chapman PB, Hauschild A, Robert C, Haanen JB, Ascierto P, Larkin J, Dummer R, Garbe C, Testori A, Maio M, et al: Improved survival with vemurafenib in melanoma with BRAF V600E mutation. N Engl J Med 364: 2507-2516, 2011.

24. Hauschild A, Grob JJ, Demidov LV, Jouary T, Gutzmer R, Millward M, Rutkowski P, Blank CU, Miller WH Jr, Kaempgen E, et al: Dabrafenib in BRAF-mutated metastatic melanoma: A multicentre, open-label, phase 3 randomized controlled trial. Lancet 380: 358-365, 2012.

25. Tafinlar ${ }^{\circledR}$ receives FDA Breakthrough Therapy designation for non-small cell lung cancer with BRAF mutation. GlaxoSmithKline, London, 2013. http://us.gsk.com/enus/media/press-releases/2014/tafinlar-receives-FDA-breakthroughtherapy-designation-for-non-small cell-lung-cancer-withbraf-mutation/. Accessed January 13, 2014.

26. Kim KB, Cabanillas ME, Lazar AJ, Williams MD, Sanders DL, Ilagan JL, Nolop K, Lee RJ and Sherman SI: Clinical responses to vemurafenib in patients with metastatic papillary thyroid cancer harboring BRAF(V600E) mutation. Thyroid 23: 1277-1283, 2013.

27. Falchook GS, Trent JC, Heinrich MC, Beadling C, Patterson J, Bastida CC, Blackman SC and Kurzrock R: BRAF mutant gastrointestinal stromal tumor: First report of regression with BRAF inhibitor dabrafenib (GSK2118436) and whole exomic sequencing for analysis of acquired resistance. Oncotarget 4 : 310-315, 2013.

28. Robinson GW, Orr BA and Gajjar A: Complete clinical regression of a BRAF V600E-mutant pediatric glioblastoma multiforme after BRAF inhibitor therapy. BMC Cancer 14: 258, 2014.

29. Bautista F, Paci A, Minard-Colin V, Dufour C, Grill J, Lacroix L, Varlet P, Valteau-Couanet D and Geoerger B: Vemurafenib in pediatric patients with BRAFV600E mutated high-grade gliomas. Pediatr Blood Cancer 61: 1101-1103, 2014.

30. Samuel J, Macip S and Dyer MJ: Efficacy of vemurafenib in hairy-cell leukemia. N Engl J Med 370: 286-288, 2014.

31. Munoz J, Janku F, Cohen PR and Kurzrock R: Erdheim-Chester disease: Characteristics and management. Mayo Clin Proc 89: 985-996, 2014.

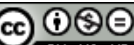

This work is licensed under a Creative Commons Attribution-NonCommercial-NoDerivatives 4.0 International (CC BY-NC-ND 4.0) License. 